\title{
Terminology: The department of speech
}

\section{J. P. Ryan}

To cite this article: J. P. Ryan (1918) Terminology: The department of speech, Quarterly Journal of Speech, 4:1, 1-11, DOI: 10.1080/00335631809360641

To link to this article: http://dx.doi.org/10.1080/00335631809360641

曲 Published online: 05 Jun 2009.

Submit your article to this journal

III Article views: 13

Q View related articles $₫$

4 Citing articles: 1 View citing articles 


\title{
THE QUARTERLY JOURNAL OF SPEECH EDUCATION
}

VOLUME IV

JANUARY, 1918
NUMBER I

TERMINOLOGY: THE DEPARTMENT OF SPEECH ${ }^{1}$

\author{
J. P. RYA.N \\ Grinnell College
}

$\mathrm{O}^{\mathrm{s}}$

F ALL those who have taught the noble art of speaking well the most influential has been Quintilian. This teacher never tired of warning against the dangers of speaking on a word or a name; but was ever urging the practice of speaking to a thesis or proposition. This practice became a principle of great virtue among the Greek rhetoricians. The classic warning comes first to mind when one looks at the words, "Terminology: Department" assigned by the programs committee. With this assignment doubly pertinent is the ancient counsel, for our present task is to find the most appropriate word. Let us, then, follow the classic advice and make out of our assignment a proposition. And the first proposition we shall speak to is:-the most desirable name for our work is department of speech.

There is no proposition today, great or small on any educational policy which is not colored by the great crises in the lives of nations, and by the new epoch into which our own national life is entering. If Prussia, putting aside the highest side of education, sacrificing the highest development of character, if Prussia, had not organized the university curricula on the system of material efficiency the world would not now be in the throes of this terrible war. If German professors had done their full

${ }^{1}$ This paper was read at the annual meeting of the National Association of Academic Teachers of Public Speaking." 
duty; if they had served Truth with half the loyalty they served dynastic success, they would not now be damned by all good men and true; they would not now be apostates of Truth, and outcasts of civilization. No excellency of German scholarship can ever atone for the terrible prostitution of that scholarship in its efforts to justify barbarism and condone military atrocities. First let it be said, without any qualifications, or mental reservations whatsoever we will win the war. Prussia and all her works must be crushed and beaten to death, or there will be no educational policy to talk about. Now we are ready to go into a discussion of any educational policy. Educational policies and the educated classes are in the deepest sense in this war. In England Lord Ramsay says: "It will do us no good to win the Great War unless we reform ourselves and remodel our education."*

In our own country educational changes and educational policies are the commonest topic of daily conversation. In all this talk the question of curriculum adjustments is receiving much attention. Any changes in a departmentally organized curricula offers to the teachers of speaking a notable opportunity. As many teachers of speech are now rising to the opportunity, and are doing loyal service as "4 Minute Men"; so there opens another opportunity to rise to a larger loyalty and out of the curriculum adjustments now going on, to secure for their subject a better recognition, and a more appropriate place in the colleges of our country. All that we have to say about a title for our department is said under the thought of present day curriculum adjustment.

We have now a proposition to wit: the most desirable name for our work is department of speech. We are all looking at this proposition from the same point of view: namely curriculum adjustments. We are, then, all ready together to go over the top into the no-man's land of discussion.

Let us lay aside all paraphernalia we shall not need. We will not use any ideas about the Terminology of the subject in general, nor the name of fundamentals. We are not now interested in technical names for research; nor are we concerned with the question of restating rhetoric in the terms of psychology. We will give no attention to that very pressing problem of the names

*Lord Ramsay: The making of a University-rgIs. 
of courses, and their standardization. None of the problems of terminology in the high school are here to be considered. Nor do we wish to be drawn into the debate about the absolutivity of names in science and the relativity of names in art. Nothing can draw us away from the original purpose of discussing the best title for our department under the light of present curriculum changes.

The most cursory examination of college catalogues reveals a variety of names. In one group of colleges the title is Public Speaking. Its variants are: Public Speaking and Debating; Public Speaking and Reading; Public Speaking and English; Public Speaking and Argumentation; Public Speaking and Oratory. What think you is meant by that phrase Public Speaking and Oratory? In another group of colleges the name of our department is English. Fortunately the variants are more numerous than the standard. The chief variants are: Oral English; Vocal English; Spoken English; Special English; English and Debating; English and Public Speaking; English and Rhetoric; English and Literature. In a small group there are a number of colleges which hold to that good old word Oratory. It, too, has many variants: Oratory and Expression; Oratory and Composition; Oratory and Rhetoric; Oratory and Vocal Culture. Two colleges still retain that much abused word Elocution. Other names in use are: Department of Speech; Department of Oral and Written Composition; Department of the Science and Art of Expression. Such a multitude of names gives our work the unique distinction of having the largest number of titles. No other department in the curriculum is known or unknown, under so many different names. So many titles lead the layman to enquire; "Why so many names for the same thing?" While our academic brothers question: "Is the same thing being taught under so many different titles?" The members of our own order pass by the multitude of names with: "So many names may indicate different points of view, different pedagogy, or different emphasis." But the matter is not to be passed over thus lightly. A multitude of names does not suggest clarity and certainty in the mind of the layman; while in the mind of the college men the very multitude is taken as evidence of the unsatisfactory educational values of the work, or proofs of the inadequate scholarship 
of the teacher. Worst of all those who are now studying without prejudice, and without malice, the college curricula are not given the right ideas of our work. The present status, then, is far from satisfactory, and more uniformity in the title of the department is greatly to be desired.

By way of digression it is not quite inappropriate to introduce at this point an astounding bit of rebuttal. The other day I told a friend of the review of catalogues which revealed a multitude of names for this department. His reply was that the work was not academically essential; and the departments were not bona fide. The teachers in the so-called departments had no voice in the college government; did not receive a share of the budget; and have very little to say in the administration of their own affairs. If such conditions exist, and there is evidence to believe such conditions are not unknown, then in the words of Koko, "Here's a pretty howdy do!" Here a subject which from the days of the Universitas Studii Generalis, which was the mother of modern colleges, down to the present, has held a well recognized place in every plan of liberal education, yet the subject today is regarded by some curriculum makers as non-essential. The work in speech is thrown into a so-called department which is really a catch-all, or an advertising scheme. At best this department is used to establish a balance between the principle, the college is a place of mental discipline, and the principle of the college is a school of general experience. If there are men in our faculties who entertain this attitude toward our work, and there are; if there are among us teachers with such academic ideals, and there are, then it is incumbent upon us to set up reputable scholastic standards, to find a reputable name for our department, and all together to demand and to command the academic respectability of both name and subject.

In returning to the data, collected from the current college catalogues, the names in each group may now be considered. Note first the English group. English is not a desirable name. The anomaly of courses in Anglo-Saxon, Celtic, aesthetics, composition, and literature under the name English has long been apparent. Plans for the reorganization and renaming of the English work in the college curriculum are slowly maturing. Teachers of literature, language, and composition find the word 
English not altogether satisfactory; while the teachers of speech find the word not only unsatisfactory but undesirable. To make the word cover the work in speech only adds to the confusion; as for denoting the department "English" is not a name, it is camouflage.

None of the variants such as Oral English, Spoken English, Special English are, in the college curriculum, desirable titles. In a liberal arts college the work in speaking plays too great a part to be isolated or stored away as an annex to any other department. Speech is the one department which by its very nature can best connect all the other departments, and help do away with the evils of a departmental curriculum. Speech has not only its own field of knowledge but it is also the ready servant in all the other fields of knowledge. Our special contribution in the curriculum is correlation. But correlation postulates equalization. You cannot correlate inequalities. You must, therefore, have separate organization. Without a separate department effective work and healthy growth will never be realized. The department of speech must be organized independently, upon its own foundation, with its own name. But it must never be forgotten, and it cannot be too often repeated; separation alone spells death. Only by separation and correlation will the department of speech come to its own in the college curriculum, and at the same time help the curriculum to come to its own in making its full contribution to the liberal education of the students. Any title including the word English is undesirable because the presence of that word vitiates the two cardinal principles of separation and correlation which must be freely operative in a departmentally organized curriculum.

Another objection, under the viewpoint of this paper, to the word English is its lack of meaning. There is no working consensus of opinion about its denotation. With other titles such as history, sociology, psychology, the members of the college family may entertain different ideas about the exact meaning of the words; but the whole faculty have a pretty general agreement about the work done under the titles. There is no such agreement about the work done under the English names. Take for example the name with a great vogue, Oral English. With some Oral English means an oral parallel of the worth of the English 
department; with others it means a method; or a bit of procedure; with still others it is restricted to elementary public speaking. In a college what does Oral English mean? or the more pertinent question for the guardians of the college curriculum, what is being done under that name? The word oral, both in its derivation and denotation is not quite desirable. In the catalogues of other colleges, than liberal arts, the word oral has a certain vogue, and reputable usage. There is, too, in the schools a well organized and successful oral movement which has very little if anything to do with speech or speaking.

But above and beyond all these arguments is the final objection that the problems of speech are no more English than they are French, German, or Russian. There is a large field of problems in speech investigation, as there is a substantial body of practices in speech cultivation which are underneath or common in all languages. As our country is now rounding into the new era we are becoming more internationally minded, more and more a nation of linguists. There is a growing demand for better instruction in the modern languages. In this new day the teachers of speech ought to make some contribution. Phonetical studies are as important as expression. Interpreting a French poem, or giving a Greek play quite as properly concerns the department of speech as interpreting an English poem or giving an English play. Some time ago in a certain college correlation was made with the department of Greek. In this work the study of the Greek drama was made from the point of view of presentation, and the tragedy of Antigone was finally presented in Greek. Such a course could hardly be called English. The word English in the title of this department is not only an inaccuracy but a hindrance to close correlation with other departments in the college.

The terms Oratory and Expression, Speech arts, and Elocution may be passed over and rejected because of their connotations. With the phrase Oratory and Rhetoric, or Rhetoric and Oratory the problem is not so simple. Both the words are old and worthy. Their champions love to point out the honored past, the wide-spread usage in many languages, the well earned place in all good dictionaries. Rhetoric as the science and Oratory as the art of expression at one time was in reputable usage in our colleges. The name is still preserved in many of the older foun- 
dations to bring the phrase, with its full meaning into present usage takes time and energy which should be spent upon the work of the day. Such an effort is like Mark Twain's experience with the whistle on the Mississippi steamboat. The boat had to be stopped to blow the whistle. Any phrase which requires explanation or justification violates the principle of economy.

The only other phrase which has received serious consideration as a title of our department is public speaking. Public Speaking seems to be a popular designation of the work rather than an official name of the department. It has a greater vernacular than documentary usage. It has not yet won its way into the Standard dictionaries. It is a phrase of protest rather than of denotation. It came in as a protest against a tendency which was turning the mind toward the past. College men did not desire courses in the history of oratory; they demanded instruction in the practical art. But more especially the phrase came in as a protest against a certain style and subject-matter. In this sense of a protest it still has popular currency. The phrase public speaking is growing into a rich and worthy significance as the name for instruction in speech making; but as a title for the department this phrase is too narrow, indefinite, and easily perverted.

The title public speaking hinders rather than helps towards a right recognition of the department in the curriculum. The hindrance comes out of an attitude of mind of the teacher of speech towards his subject, and out of the attitude of mind of the other members of the faculty towards the subject of speech. Both of these statements need amplification. The teachers of speech must more and more take an intellectual attitude toward their work. If the work of the spoken word is to secure a permanent place within the precincts of higher education that work must become more and more an intellectual pursuit. By intellectual pursuit is not meant merely mental discipline. The work in speaking can be made the most difficult course in the curriculum. It is true public speaking is the best training in public thinking. It is readily admitted that the work is peculiarly fitted to develop the powers of a student. One can freely grant that there is no other subject in the curriculum which lends itself more readily to the task of enlightening the spirit, evoking the will, and 
sharpening the faculties; withal of lifting the student to that high plane on which he can function with his greatest efficiency. All of these are desirable and proper, but there is more in looking at the subject as an intellectual pursuit. There are other things for which higher institutions of learning are maintained and these are the cultivation of the life intellectual, and the acquisition of knowledge. Some worthy contribution must be-made to that storehouse of knowledge which the world is unwilling to forget, and for the perpetuation of which higher institutions of learning are established and maintained. The collection and organization of knowledge is an intellectual pursuit par excellence. The department of speech in a college need not, indeed should not, concern itself with scholarship in the sense of developing and applying creative ability. This is the special function of the graduation school. But the department of speech should be so organized and so named as to let pupils while in college know that there is a higher field of specialized study, and that there are opportunities for creative ability along the lines of science, as well as along the lines of artistic performance. The development of the life intellectual is a concommitant desideratum. The more one grows in the intellectual life the more one learns to deduce from the body of his organized knowledge that which is good for the whole, and that which is permanent, and not take something good for a particular few, or spend the time in advertising a method, or exploiting a man. This is what it means to look at the subject as an intellectual pursuit. This is the attitude of mind the teachers must take or be debarred from that circle in which men follow the intellectual life. If the members of this department have nothing to teach but procedure, dexterity, conventions, and nothing to talk about in their association meetings but methods then their days are numbered, and their influence is measured. The first criterion of an intellectual attitude is the impersonal. It is of no great importance what this or that person feels or thinks, nor the way that individual works. Only the genius of the whole will ever save from the folly of the few. There is overmuch talk about methods. The subject of speech is concerned so much with the application of knowledge that there is a tendency to over-emphasize that side of the work. And just because the phrase public speaking emphasizes the doing rather than 
the knowing, therefore some other phrase should be found which would equalize the stress and give some emphasis to the subject as an intellectual pursuit.

The state of mind found in the other members of the faculty is the other serious obstacle which hinders the subject from coming to its right place in the curriculum. In the minds of those who control the curricula the phrase public speaking means the practice of an art. To a man looking for graduate work in an eastern university the head of the graduate school replied that there was no work offered because speaking was merely a bit of technique. In that man's mind, and in the mind of every other man in that graduate school public speaking meant the practice of effective speech making. To another man working on the phonology of Burke's speech the instructor gave warning against the use of the term public speaking for that phrase meant the art of delivery, or declamation. Another eminent scholar in talking about a vocation advised against teaching public speaking for he reasoned that there were no opportunities in that field for scholastic endeavor. At best public speaking was the teaching of dexterity, at worst the teaching of conventions. Illustrations ad infinitum could be complied to show that in the mind of all the leading scholars and college presidents the meaning of the phrase public speaking is fixed. That attitude of mind is a serious barrier against the subject ever coming to its proper place in the curriculum. Of course it must never be thought that any word is an open sesame to a place of service and power. Work is the only way. And work, well done, under any name must win. The point is that any work done under the name public speaking is going to be done under great difficulty. It is easier to change the name, than the mind of some of these professors; it is wiser to do good work under some other name than public speaking.

The best title, under which to work is Department of Speech. The word speech is old, short, simple, stable, well-known, accurate, common, learned, definite, extensive, and academically acceptable for it connotes the art and denotes the science, or just as well it denotes the art, and connotes the science. The term public speaking should not be dropped. It could be kept as a sub-title, or better it should be retained for just what it is, the name of a course in the department of speech-a course devoted 
to the art of speaking in public. Small and simple as is the word speech, yet it is the only word large enough to cover the present activities, and those which are daily demanding a larger share of attention. The rising interest in the improvement of American speech, the work in speech culture, and speech defects, the work so splendidly begun by Dr. Muckey, the demands for instruction in private talk and conversation are just as legitimately the activities of this department as the work in debating or any kind of speaking in public, and either branch is as important as the work in the drama or interpretation of the printed page. All the work of the department may be grouped under three subheads: the voice, the speaking, and the interpretation. Perhaps other words as speech culture, public speaking, and dramatic art may be used, but the opinion is quite general that these are the three lines of work. The only word large enough to cover the three fields is speech.

There is no better way of realizing what are the present activities and coming opportunities than to study a collection of the phrases in which are made different statements of the purpose of this department. Note some of these phrases and think of their meaning. "The purpose of this department is to give a greater recognition to the spoken word in education; to give more emphasis to the peculiar, academic discipline of the speech sciences." "To realize more fully the educational values in the study of the speech arts." What a body of meaning back of such a declaration as this: ${ }^{6}$ In the past the emphasis has been overmuch upon the artistic, upon performance; to-day the stress should be shifted to the scientific to scholarship." Not half so radical but just as revolutionary is the statement: "As the goal of science is explanation-one of the purposes of this study is to discover knowledge of speech, and as the goal of art is action, the other purpose, is to study the art of speaking well." Some of these statements are interesting as revealing the tones of a radical. Less interesting perhaps, but more potent are those statements which echo the voice of the philosopher, or reflect larger tendencies in education. "To find out knowledge of speech, to develop the ability to think in terms of social life and social culture, to train men and women to play their part in a democracy." No one can review these statements of purposes without 
finding a clearly marked movement to stress educational values, to emphasize social relationship, and to build up a genuine scholarship by work in the field of research. This is the program of the Department of Speech.

Our people must go out from local interests to national, and international ones. In so doing changes and adjustments must be made. Not the least of these will be the adjustments of our college curricula. Now is the time for teachers of speech to reorganize and to rename their department. 